\title{
Confrontación de las fuentes estadísticas del balance fiscal en México, 1934-1956
}

\section{Confronting Statistical Sources of Fiscal Budget for Mexico, $1934-1956$}

Sergio Martín ${ }^{1, *}$ (D) 0000-0002-5877-4880

${ }^{1}$ Sergio Martín y Asociados, Consultoría Macroeconómica, México.

* Correspondencia: sergiomartin007@gmail.com

Resumen. El balance presupuestario del gobierno mexicano es el indicador principal para evaluar la política fiscal y su impacto macroeconómico. El objetivo de este artículo es confrontar las series del balance fiscal de las fuentes primarias y secundarias y discernir cuál puede ser la más adecuada en la investigación históricoeconómica de la etapa del desarrollo con inflación, 1934-1956, en México. Nuestra hipótesis señala que la fuente primaria en términos brutos que utiliza la metodología ingreso-egreso-balance no es la adecuada para evaluar la política gubernamental debido a que incluye rubros que distorsionan el balance fiscal y su impacto macro. La fuente primaria a utilizar es la que aplica la metodología del cálculo del balance fiscal vía su financiamiento. Las fuentes secundarias que usan la primera opción reproducen la deficiencia anotada, lo cual implica problemas de interpretación histórica. Al respecto, realizamos un análisis metodológico de la historiografía sobre el comportamiento de las finanzas públicas.

Palabras clave: política fiscal; balance fiscal; inflación; crisis cambiarias; impacto macroeconómico.

Abstract. The budget balance is the main indicator to evaluate the fiscal policy and its macroeconomic impact. The objective of this study is to confront the series of the budget balance provided by the primary and secondary sources and find out which is the most adequate for economic history research in the

CÓMO CITAR: Martín, S. (2022). Confrontación de las fuentes estadísticas del balance fiscal en México, 1934-1956. América Latina en la Historia Económica, 29(1), 1-26. DOI: 10.18232/alhe.1265 
period 1934-1956. Our hypothesis states that the primary source in gross terms, which is based on the income/expenditure/balance methodology, is not adequate to evaluate the government policy because it includes items that distorts the fiscal balance and its macroeconomic impact. The way to resolve this issue is to use the primary source that applies the methodology to calculate the fiscal balance through its financing. The secondary sources based on the first option reproduced the noted deficiency and affected the historical interpretation, something that is shown with a methodological analysis of the historiography on the performance of the public finances.

Key words: fiscal policy; fiscal balance; inflation; exchange rate crisis; macroeconomic impact.

JEL: N16; E51; E52; E6; H5; H6.

Recibido: 30 de octubre de 2020.

Aceptado: 15 de diciembre de 2020.

Publicado: 24 de noviembre de 2021.

Agradecimiento: a los valiosos comentarios y sugerencias de Daniel Garcés. Asimismo, deseo destacar que las observaciones realizadas por los evaluadores anónimos contribuyeron a mejorar la versión original del artículo.

\section{INTRODUCCIÓN}

Uno de los problemas de la historia económica es la confiabilidad de las cifras utilizadas para estructurar la argumentación y verificar las hipótesis de los estudios en cuestión. La importancia de las fuentes estadísticas y de su utilización es la de establecer los términos empíricos sobre los cuales la interpretación histórica se sustenta para evaluar la política fiscal y su impacto sobre la actividad económica, la inflación y las cuentas externas. Existen pocos estudios específicamente metodológicos sobre las fuentes primarias utilizadas por la historiografía que indagan los efectos financieros del Estado en el desempeño de la economía mexicana para el periodo propuesto.

El objetivo de este estudio es contrastar el conjunto de diversas cifras del balance de las finanzas públicas de México para dilucidar cuál es la serie sobre la cual fundamentar la interpretación. Este esfuerzo servirá para avanzar en la historia económica mexicana al analizar las diversas fuentes de información estadística y la metodología que las sostiene. Asimismo, nos permitirá argumentar por qué una es más confiable que la otra y hasta qué punto podemos obtener diversos resultados e interpretaciones.

La hipótesis del estudio plantea que la fuente primaria, la Cuenta de la Hacienda Pública Federal (en adelante CHPF), que produce la Secretaría de Hacienda y Crédito Público (shcp), sobre la que se basa la metodología ingreso-egreso-balance es inadecuada ${ }^{1}$ para evaluar la política fiscal por encontrarse en términos brutos. Asimismo, fuentes secundarias, como el Instituto Nacional de Estadística y Geografía [INEGI] (2020) y Nacional Financiera (1972), repiten este defecto. Esta dificultad se supera a través de: $a$ ) ajustar las cifras brutas por el rubro financiero ${ }^{2}$ y así obtener cifras netas, y $b$ ) estimar el balance público a través de su financiamiento para cubrir un déficit o

${ }^{1}$ El origen histórico y la naturaleza de la CHPF es constituir el libro de cuentas del gobierno federal y tener un seguimiento estricto de los ingresos y gastos. Sin embargo, cuando la utilizamos para otros fines, puede no ser adecuada debido a la complejidad de la contabilidad gubernamental y en particular a su formato contable y no económico. Este es el caso de la estimación del déficit público con impacto macroeconómico.

${ }^{2}$ Definimos el rubro financiero como el neto de empréstitos, amortizaciones y otros ítems que se incluyen en los ingresos y egresos de la cHPF. Más adelante se definirá con mayor precisión el concepto. 
determinar la acumulación de ahorro público cuando es un superávit. ${ }^{3}$ El déficit o superávit fiscal resultante de estas dos series tiene un impacto macro en la economía, lo que las hace adecuadas para evaluar la política fiscal. Sin embargo, la comparación de estas dos series muestra diferencias en ciertos años debido a las diferentes metodologías con las que fueron obtenidas y dan lugar a interpretaciones divergentes. Un análisis histórico en los momentos en que discrepan sugiere que la serie a través del financiamiento es más consistente.

El estudio abarca desde 1934 hasta 1956, periodo generalmente denominado en la literatura como la "etapa de crecimiento con inflación", en contraposición a la etapa de "crecimiento con estabilidad de precios" de 1956 a 1970. Esta periodización y designación la propuso Solís (1970, p. 109) con base en que el periodo de estudio mostró en promedio un alto crecimiento y la distinción analítica desde el punto de vista económico es la estabilidad o la falta de ella en los precios. Esta diferencia permite una división temporal pertinente en términos de la política económica, especialmente la fiscal, debido a la importancia que tuvo en el periodo de estudio el déficit gubernamental para explicar la inflación y sus consecuencias en las crisis cambiarias observadas. ${ }^{4}$ Las definiciones de variables y las fuentes estadísticas las enfocaremos a los ingresos-egresos-balance del gobierno federal. ${ }^{5}$ Estas variables son las determinantes para evaluar la política fiscal de las administraciones incluidas en el periodo.

El contexto histórico del periodo en estudio es el del momento en que la sociedad y economía transitan hacia un nuevo modelo de desarrollo. Las posiciones sobre política económica iniciaron un giro hacia una política de corte keynesiano que coincidía con el intervencionismo estatista de la época (Suárez, 1977a). Las grandes necesidades de México incentivaban una política expansiva. Suárez, secretario de Hacienda, propugnaba por un mayor gasto, incluso a costa de la estabilidad monetaria, en aras de un desarrollo económico más acelerado y con una mejor distribución del ingreso. ${ }^{6}$ El país avanzaba, pero sujeto a crisis cambiarias en 1938, 1948 y 1954 y a los choques externos de la segunda guerra mundial y la guerra de Corea. En suma, un periodo de alto crecimiento, pero con inflación y crisis cambiarias.

Este estudio comprende cuatro apartados y las consideraciones finales. En el primero hacemos algunas precisiones sobre el contenido de conceptos relevantes. En el segundo mostramos el problema de utilizar las series brutas del balance fiscal que proviene de las fuentes primarias y secundarias. En el tercero mostramos las dos series netas de las fuentes primarias como las más adecuadas y hacemos un ejercicio comparativo para discernir cuál de ellas es más precisa. Mientras que en el cuarto apartado se muestran los problemas de utilizar series secundarias para la investigación histórico-económica debido a su falta de precisión, lo cual ilustramos con un análisis de la interpretación que realiza Cárdenas (1994, 2008 y 2015) al utilizar la fuente secundaria del INEGI (2020), y en las consideraciones finales ofrecemos el balance de los hallazgos de la investigación.

${ }^{3}$ La fuente original de esta información es Banco de México (1940-1963), dada la función del banco central como agente financiero del gobierno federal. El monto se calcula con las variaciones de deuda interna y externa, así como el movimiento de disponibilidades y se define más formalmente líneas abajo.

${ }^{4}$ Esta periodización es común en la literatura macroeconómica desde su propuesta en 1970. Varios autores la utilizan en sus estudios, entre otros, Reynolds (1977), Cárdenas (1998, 2015) y Moreno-Brid y Ros (2010).

${ }^{5}$ La información estadística fiscal se encuentra en términos nominales y se expresa generalmente como proporción del PIB nominal en los cuadros 1-5.

${ }^{6}$ El secretario de Hacienda Francisco Suárez (1977, p. 411) señaló en la respuesta a un debate que sostenía con el exsecretario de Hacienda Pani que "el problema supremo de México no está en lograr la estabilidad monetaria [...] en el terreno económico consiste en lograr la elevación del ingreso nacional [...] alcanzándose hasta donde eso es posible, una mejor distribución de dicho ingreso". 
Por último, en los cinco cuadros incluimos las distintas series bajo análisis. Las cifras que se citan a lo largo del estudio provienen de estos mismos cuadros y se definen conceptos económicos clave cuando son mencionados por primera vez en el texto.

\section{Algunas PREGISIONES SOBRE EL CÁLCULO DEL BALANCE FISCAL Y SU IMPACTO EN LA ECONOMÍA}

Ofrecemos como preámbulo una breve descripción de la macroeconomía de las finanzas públicas desde el punto de vista de la economía convencional e introducimos el tema de las metodologías para obtener el balance fiscal y su naturaleza de ser brutas o netas.

La política fiscal en términos macroeconómicos se juzga generalmente a partir del balance de las finanzas públicas. Es cierto que hay estudios que analizan aspectos particulares sobre las políticas impositivas, de inversión o industrial, pero el principal indicador macro de la política fiscal es la diferencia entre sus ingresos y egresos, es decir, su balance. Esto no implica que aspectos como la eficiencia del gasto o de la recaudación sean menos importantes, sino que dicho balance es la referencia agregada del impacto gubernamental en la economía. En efecto, los ingresos del gobierno provienen principalmente de los impuestos al sector privado y sus egresos se ejercen en salarios, inversión y otros. Por tanto, si hubiera un equilibrio entre ingresos y egresos, el impacto macro sobre la demanda agregada sería prácticamente nulo, ya que los recursos que el sector privado se hubiera gastado de no haber pagado impuestos, ahora los gasta el gobierno. Si hubiera menores egresos que ingresos, o sea, un superávit fiscal, entonces se estarían extrayendo recursos del sector privado para aumentar el ahorro público, lo cual tendría una consecuencia negativa para la demanda agregada. Igualmente, un déficit fiscal, en el que el gobierno vierte más recursos en la economía que los que obtuvo por medios impositivos, tiene un impacto positivo en la demanda agregada, la cual, si no se encuentra en pleno empleo, presenta la posibilidad de un estímulo a la actividad económica (Krugman y Wells, 2013).

Hay dos vías de medir el balance público, las cuales deberían rendir el mismo resultado, pero generalmente presentan una discrepancia. La primera es a través de la contabilidad de ingresosegresos-balance y la segunda es a través del financiamiento del balance, el cual, si es positivo, representa un ahorro del gobierno, y si es negativo, representa recursos que se tienen que obtener a través de endeudamiento interno o externo. El Banco de México (1949) lo define de la siguiente manera:

Existen dos procedimientos para estimar el déficit o superávit gubernamental: el directo, que consiste en determinar la diferencia que exista entre los ingresos y egresos efectivos [...] y el indirecto mediante el cual se obtiene dicha diferencia deduciendo del incremento de las deudas contraídas durante el año, que hayan significado una transferencia de fondos al gobierno, los pagos por amortización de deuda o cancelación de créditos y la variación de las disponibilidades en efectivo (p. 45). ${ }^{7}$

En adición, el Banco de México (1952, p. 56) se explaya en su metodología al explicar la determinación del balance fiscal. La contabilidad directa de ingresos-egresos no es precisa debido a los innumerables rubros que la componen y su complejidad, lo que la sujeta a correcciones en los

${ }^{7}$ Véase Anguiano (1968) para una explicación más detallada. 
años posteriores a la finalización del año que corresponde, las cuales no necesariamente enmiendan esa imprecisión. ${ }^{8}$ Asimismo, no todos los rubros de la contabilidad tienen un impacto macro en la economía; por ello, hay series brutas, las cuales incluyen subsidios, empréstitos y amortizaciones, entre otros conceptos, y otras series netas que excluyen dichos conceptos. En detalle, las series brutas incluyen rubros adicionales. En los ingresos brutos, los subsidios, los ingresos virtuales, los empréstitos y la recuperación de capital; en los egresos brutos, los subsidios compensados con egresos, otros egresos virtuales, amortización de deuda, egresos pendientes de pago y egresos compensados con recuperación de deuda. El excluir estos rubros en los ingresos y egresos rendiría lo que se denominan ingresos efectivos ordinarios de ley y egresos efectivos pagados, respectivamente. El cálculo del rubro financiero neto de estos ingresos y egresos se toma de Santillán y Rosas (1962), quienes hacen una descripción detallada de los componentes adicionales. En suma, los ajustes para obtener datos netos nos acercan más adecuadamente a los ingresos y egresos públicos, que reflejan mejor el impacto macro en la economía. Por ejemplo, si consideramos los empréstitos en los ingresos, estos serían mayores y el efecto en el balance fiscal sería hacerlo más positivo y viceversa con las amortizaciones, lo cual distorsionaría el impacto macro. ${ }^{9}$ Igualmente, por ejemplo, al considerar los subsidios compensados en los ingresos y egresos, no habría cambio en el balance, pues se compensan mutuamente; no obstante, sí distorsionan los ingresos y egresos cuando estos se analizan por separado. ${ }^{10}$

En consecuencia, el balance fiscal de la serie por el primer procedimiento descrito no coincide con el segundo por haber sido calculados con diferentes metodologías. La vía del financiamiento o indirecta en principio debería ser más precisa, pues su contabilidad se tiene más oportunamente y toda ella tiene un impacto macro. Esta representa el exceso-reducción del gasto respecto a los ingresos, el cual se manifiesta en las variaciones de la deuda interna y externa y el movimiento de disposiciones del gobierno. El ejercicio y control del financiamiento lo hace el Banco de México, quien es el agente financiero del gobierno.

Las fuentes estadísticas primarias de las variables fiscales son la Secretaría de Hacienda y Crédito Público y el Banco de México. La primera produce la serie de ingresos-egresos-balance del gobierno federal, y la segunda ofrece una cuenta del balance fiscal del gobierno federal vía el financiamiento del mismo.

\section{SERIES PRIMARIAS Y SECUNDARIAS BRUTAS}

La Secretaría de Hacienda y Crédito Público registra las series de ingresos-egresos brutos en la CHPF. En este estudio consultamos las 30 ediciones anuales iniciales correspondientes al periodo 1934-1963, con la extensión hasta 1963 para incluir las correcciones posteriores hasta por cinco años. Las otras estadísticas de finanzas públicas provenientes de la SHCP fueron las elaboradas por la denominada entonces Dirección General de Planeación Hacendaria (DGPH) de la Secretaría de

${ }^{8}$ La fuente primaria chPF presenta sus cifras siete meses después del cierre del año al que corresponde y posteriormente emite correcciones hasta por cinco años. Por ello, hacemos la distinción entre su edición inicial y revisada. La serie inicial que presentamos incluye la que se publicó en la edición de la chpF del año y que se da a conocer el 31 de julio del año siguiente. La serie revisada recoge los datos que se publicaron cinco años después y este es el que consideramos definitivo para formar la serie revisada.

${ }^{9}$ Anguiano (1968) detalla los ajustes necesarios para pasar a cifras netas.

${ }^{10}$ Por ejemplo, si quisiéramos utilizar los ingresos del gobierno para escalar cualquier otra variable, por ejemplo el balance fiscal, el considerar los subsidios compensados distorsionaría nuestro indicador. 
Hacienda y Crédito Público. Esta fuente tiene como característica relevante que se distingue de la serie de la CHPF por contabilizar los ingresos y egresos pagados y cubiertos el año calendario correspondiente, independientemente del ejercicio fiscal al que se refiera. Las series de ingresosegresos de la DGPH tienen diferencias sustanciales con la serie inicial de la CHPF. Respecto a la serie revisada de la CHPF los ingresos son semejantes, pero los egresos difieren notablemente. Suponemos entonces un grado importante de inconsistencia de las series de la DGPH y la posibilidad de que incluyan los rubros sin impacto macro de las series de la CHPF en su versión inicial y revisada y por lo mismo no son adecuadas para el análisis del balance fiscal. No obstante, sus datos se incluyen en los cuadros 1, 2, 3, 4 y 5 para las comparaciones que se consideren pertinentes.

Las series inicial y revisada para los ingresos difirieron sustancialmente en 1941-1943, 1945 y 1947-1948; en el caso de los egresos en 1937-1938, 1940-1943, 1946 y 1950-1951, 19531954 y $1957 .{ }^{11}$ Esto implica que utilizar la serie inicial lleva a imprecisiones durante ciertos años, ya sea por el lado de los ingresos o el de los egresos. En algunos años las discrepancias de unos y otros se cancelan, pero en otros se incrementan. En al menos $40 \%$ de las observaciones existe una diferencia significativa, lo que conduce a cierto grado de error en el cálculo del balance fiscal. Específicamente en 1936-1937, 1940, 1943, 1945, 1947-1948, 1950-1951 y 1954.

En el planteamiento principal del estudio señalamos que la fuente primaria de la cHPF es inadecuada para evaluar la política fiscal por encontrarse en términos brutos y medir erróneamente el impacto macro. En consecuencia, se descarta la utilización de las series primarias que son brutas por este argumento metodológico, ya sea que se trate de la versión inicial o revisada de las series de la CHPF.

$\mathrm{El}$ argumento empírico es que el rubro financiero es de una magnitud importante en ciertos años, tanto en ingresos como en egresos, y aun cuando en el balance algunas discrepancias se anulan parcialmente, otras se incrementan en magnitud. En efecto, el tamaño promedio del rubro financiero en ambos, ingresos y egresos, es alrededor de $1.8 \%$ del PIB; por lo que el error promedio del balance de ingresos y egresos del rubro financiero se reduce notablemente a $0.3 \%$ del PIB. ${ }^{12}$ Sin embargo, en algunos años es significativo, por ejemplo en 1935, 1944, 1948-1949 y 1953-1956.

Las series de fuentes secundarias que reproducen a las series de la fuente primaria de la cHPF inicial o revisada en términos brutos tienen el mismo problema de imprecisión. Existen varias compilaciones de las estadísticas fiscales y monetarias primarias, entre las más conocidas están las estadísticas que proporcionan Santillán y Rosas (1962) (en adelante S y R) y estadísticas históricas de México (en adelante eH) (INEGI, 2020). ${ }^{13}$

${ }^{11}$ La discrepancia entre las diversas fuentes se juzga como la diferencia absoluta de las series en porcentaje del producto interno bruto (PIB). Cuando esta diferencia es mayor que el promedio de dichas diferencias en porcentaje del PIB se considera sustancial o significativa.

${ }^{12}$ Véase cuadro 5 para las cifras del PIB nominal utilizadas para calcular las proporciones del PIB.

${ }^{13}$ Se excluyen del análisis las series siguientes: a) Cárdenas (1994) y Nacional Financiera (1964) debido a que son prácticamente idénticas a las del INEGI (2020); $b$ ) Isoard (1979) debido a que sólo compila las series de la cHPF inicial bruta, y $c$ ) Aguilar (1947) debido a que sus estadísticas sólo reportan un tramo corto del periodo bajo estudio y son inconsistentes al utilizar de forma mixta los datos de las series de la cHPF en sus versiones inicial y original. 


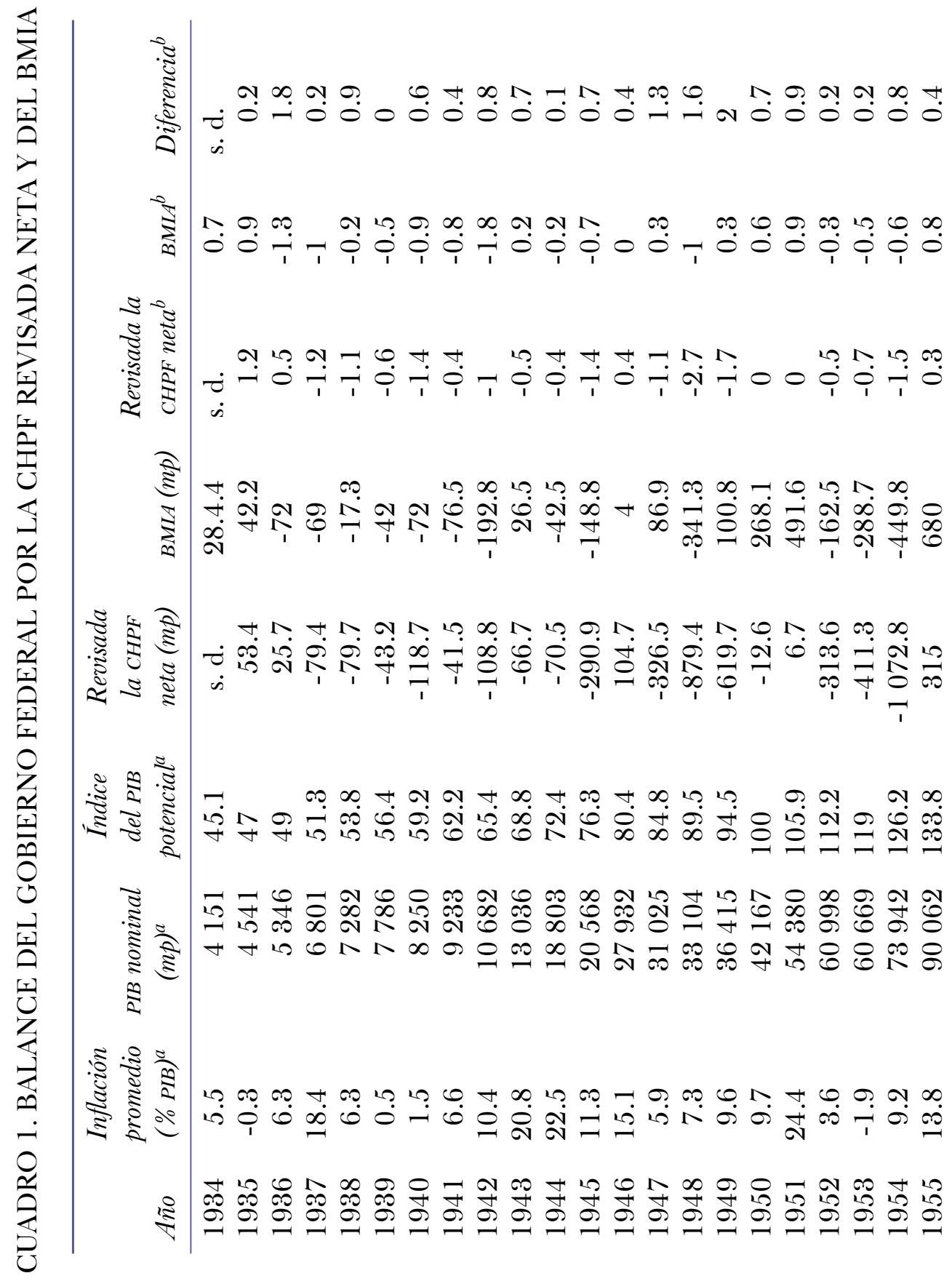




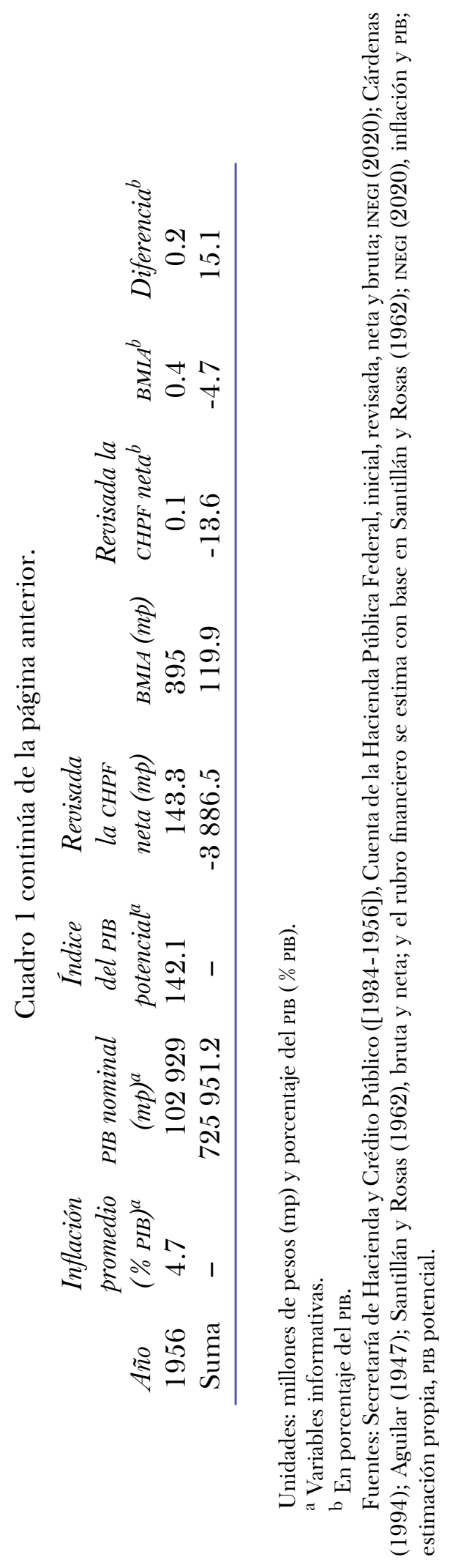




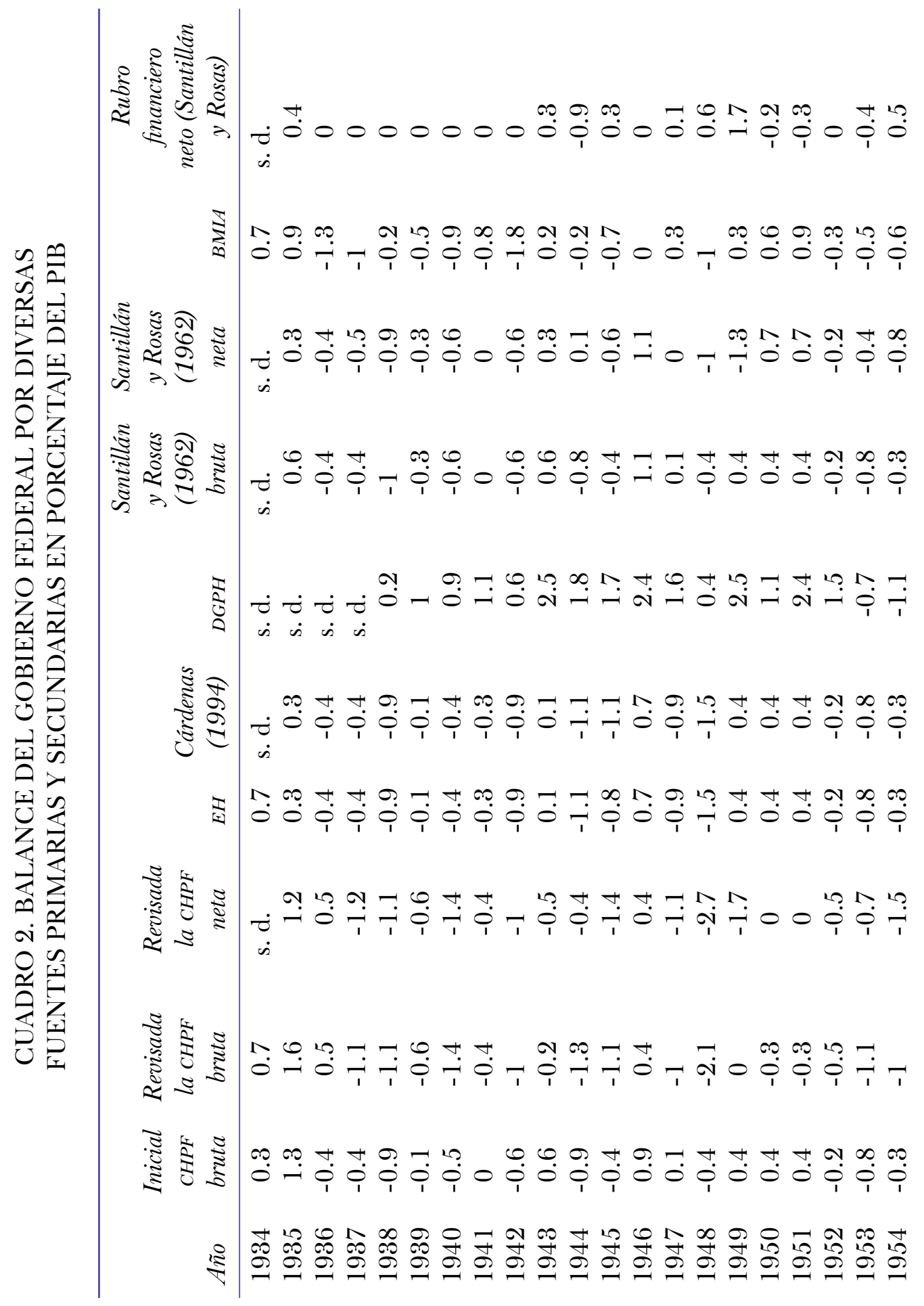




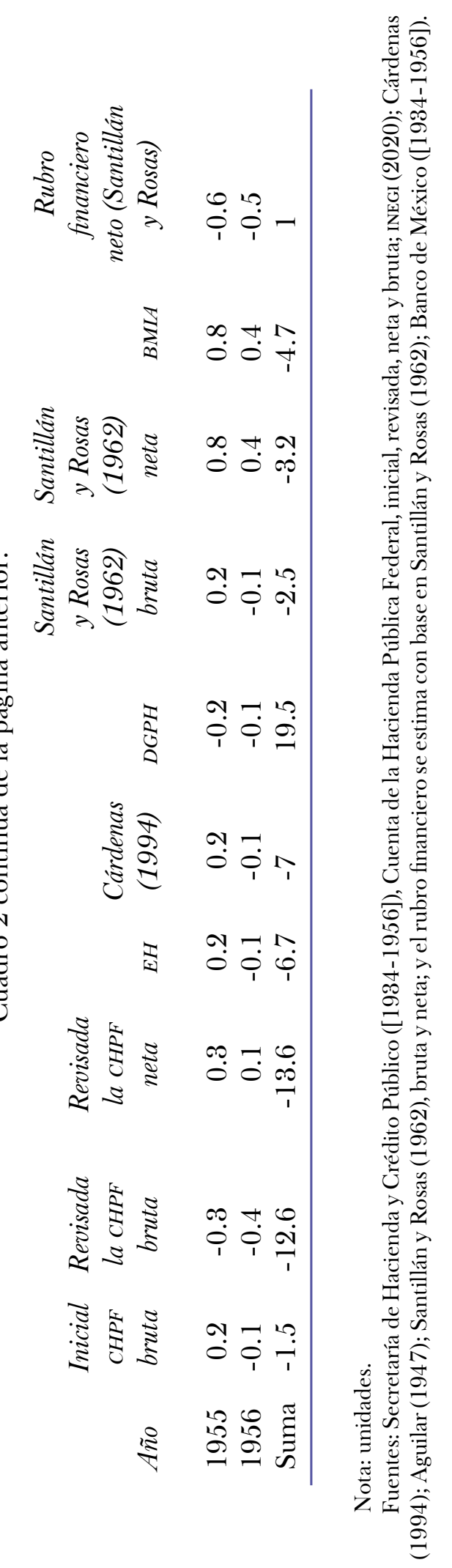




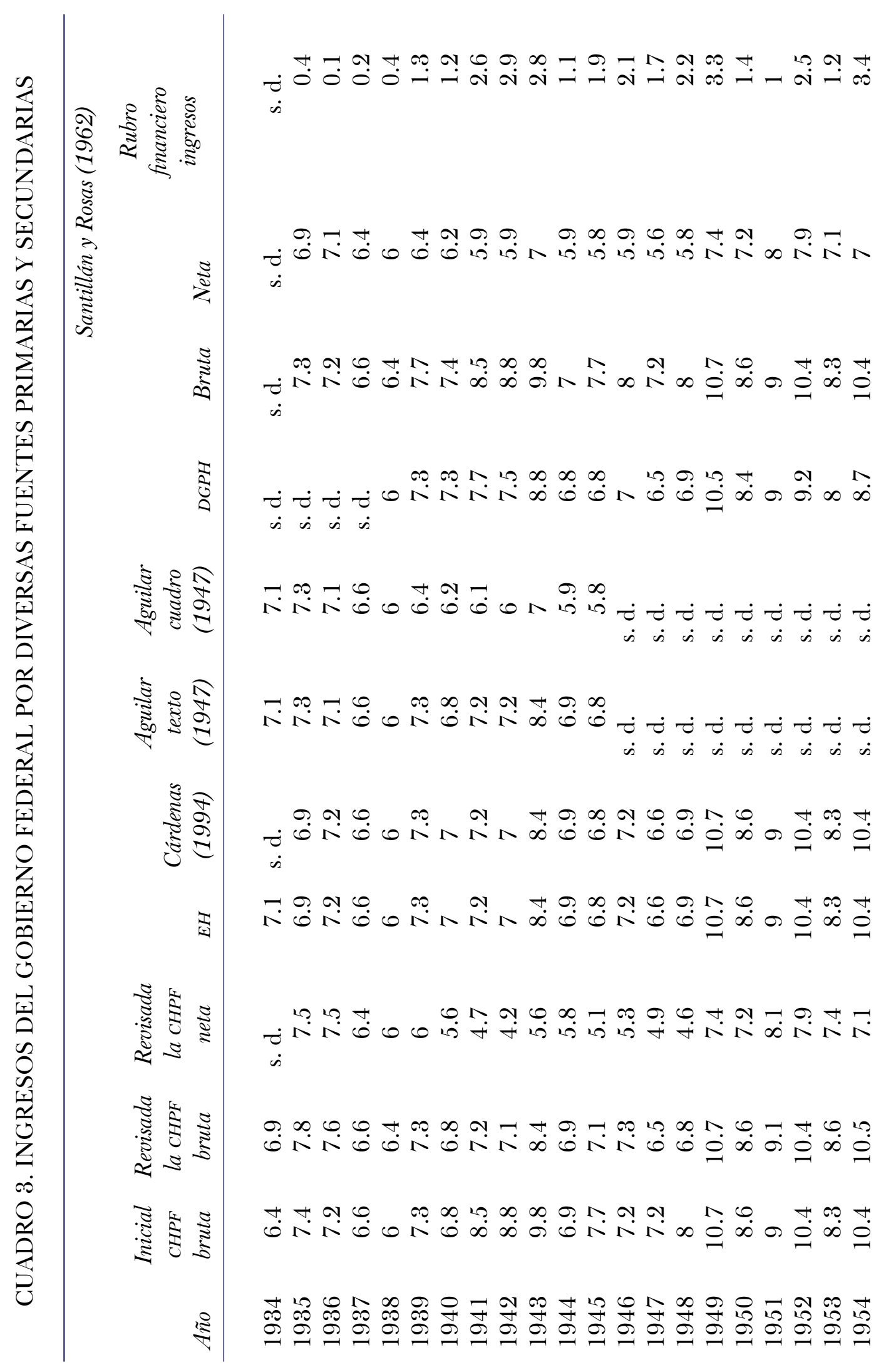




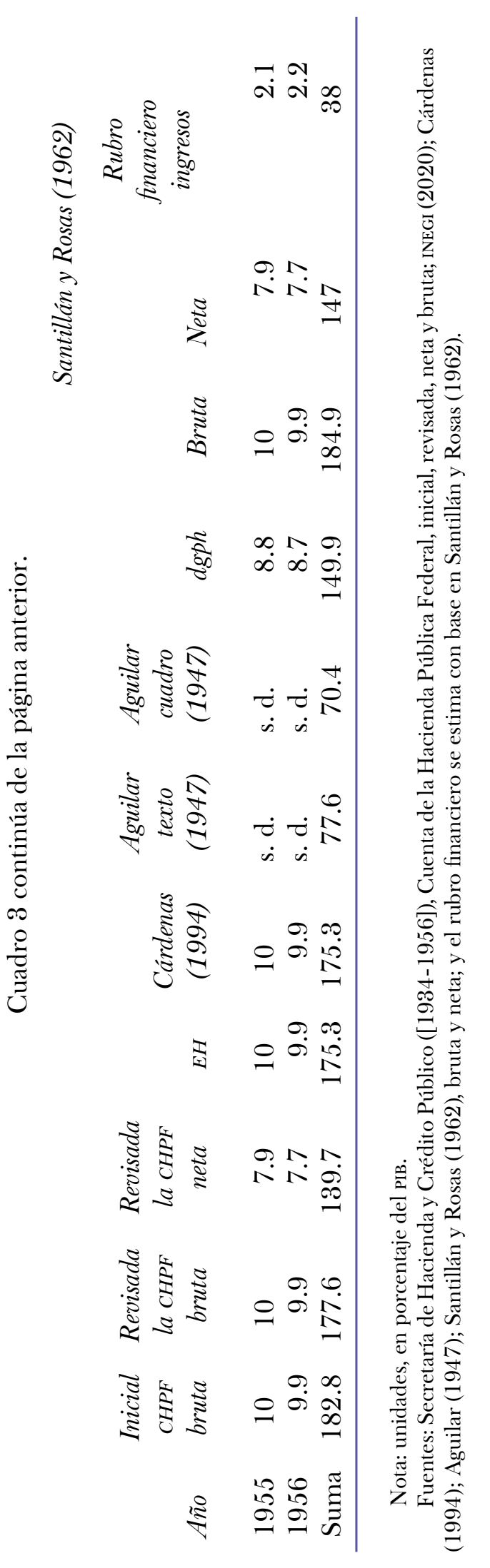




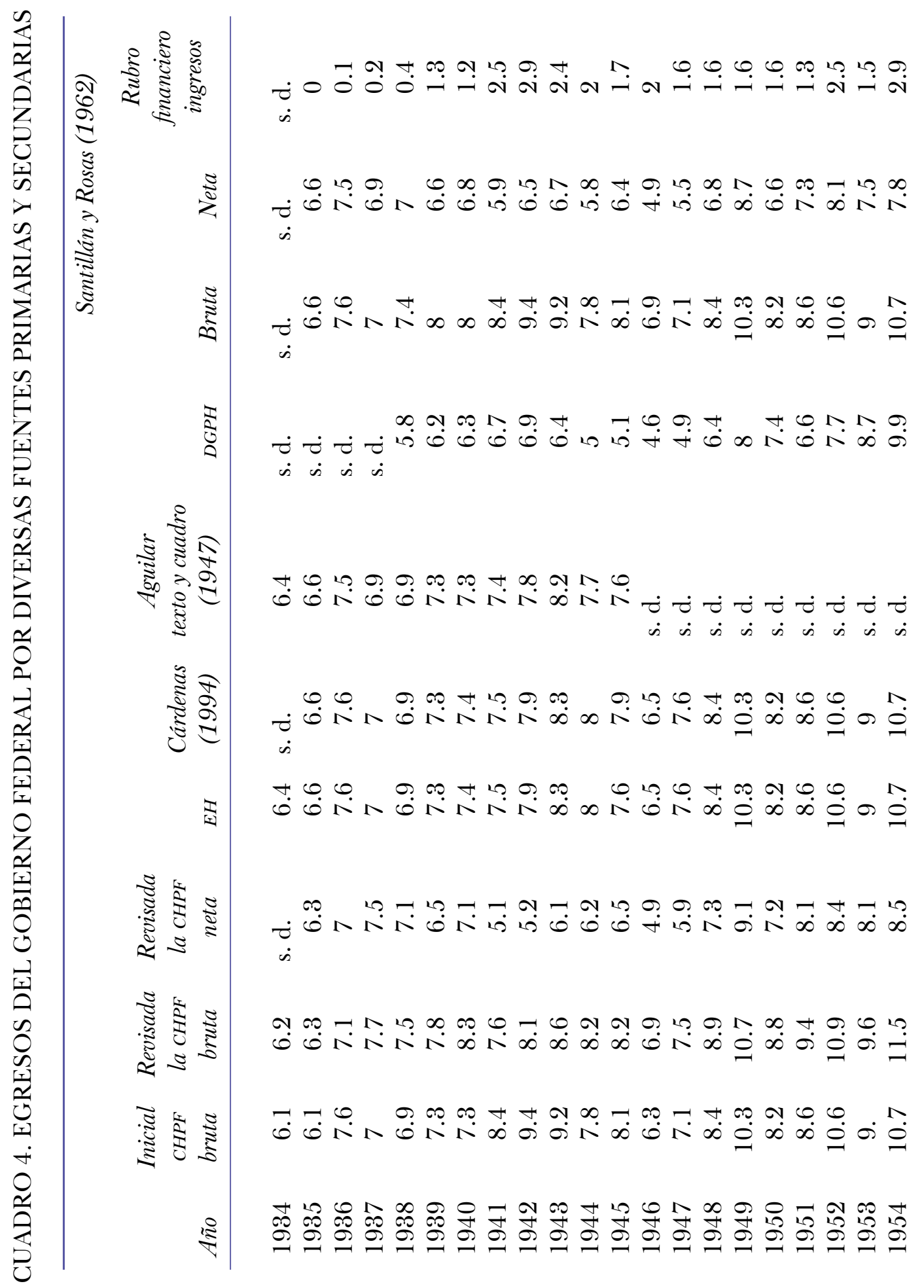




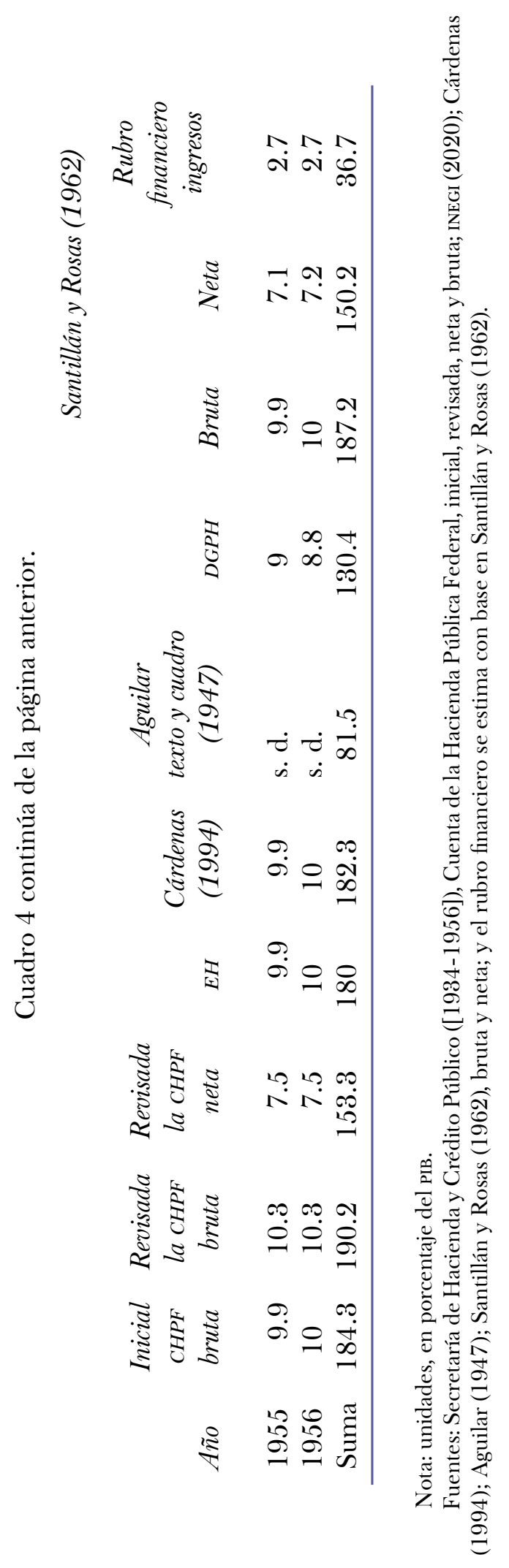


CUADRO 5. BALANCE DEL GOBIERNO FEDERAL POR EH Y BMIA

\begin{tabular}{|c|c|c|c|c|c|c|}
\hline Año & $\begin{array}{c}\text { PIB nominal } \\
\quad(m p)\end{array}$ & $E H(m p)$ & $\begin{array}{c}B M I A \\
(m p)\end{array}$ & $E H^{a}$ & $B M I A^{a}$ & Diferencia ${ }^{a}$ \\
\hline 1934 & 4151 & 30 & 28.4 & 0.7 & 0.7 & 0 \\
\hline 1935 & 4541 & 12 & 42.2 & 0.3 & 0.9 & 0.7 \\
\hline 1936 & 5346 & -21 & -72 & -0.4 & -1.3 & 1 \\
\hline 1937 & 6801 & -28 & -69 & -0.4 & -1 & 0.6 \\
\hline 1938 & 7282 & -66 & -17.3 & -0.9 & -0.2 & 0.7 \\
\hline 1939 & 7786 & -5 & -42 & -0.1 & -0.5 & 0.5 \\
\hline 1940 & 8250 & -33 & -72 & -0.4 & -0.9 & 0.5 \\
\hline 1941 & 9233 & -24 & -76.5 & -0.3 & -0.8 & 0.6 \\
\hline 1942 & 10682 & -99 & -192.8 & -0.9 & -1.8 & 0.9 \\
\hline 1943 & 13036 & 7 & 26.5 & 0.1 & 0.2 & 0.1 \\
\hline 1944 & 18803 & -210 & -42.5 & -1.1 & -0.2 & 0.9 \\
\hline 1945 & 20568 & -169 & -148.8 & -0.8 & -0.7 & 0.1 \\
\hline 1946 & 27932 & 183 & 4 & 0.7 & 0 & 0.6 \\
\hline 1947 & 31025 & -288 & 86.9 & -0.9 & 0.3 & 1.2 \\
\hline 1948 & 33104 & -505 & -341.3 & -1.5 & -1 & 0.5 \\
\hline 1949 & 36415 & 150 & 100.8 & 0.4 & 0.3 & 0.1 \\
\hline 1950 & 42167 & 178 & 268.1 & 0.4 & 0.6 & 0.2 \\
\hline 1951 & 54380 & 214 & 491.6 & 0.4 & 0.9 & 0.5 \\
\hline 1952 & 60998 & -126 & -162.5 & -0.2 & -0.3 & 0.1 \\
\hline 1953 & 60669 & -467 & -288.7 & -0.8 & -0.5 & 0.3 \\
\hline 1954 & 73942 & -203 & -449.8 & -0.3 & -0.6 & 0.3 \\
\hline 1955 & 90062 & 141 & 680 & 0.2 & 0.8 & 0.6 \\
\hline 1956 & 102929 & -76 & 395 & -0.1 & 0.4 & 0.5 \\
\hline Suma & 725951.2 & -1435 & 119.9 & -6.7 & -5.6 & 11.4 \\
\hline Promedio & 31744 & -61.1 & 6.4 & -0.3 & -0.2 & 0.5 \\
\hline
\end{tabular}

Unidades: millones de pesos (mp).

a En porcentaje del PIB. La discrepancia se expresa en términos absolutos.

Fuentes: Secretaría de Hacienda y Crédito Público ([1934-1956]), Cuenta de la Hacienda Pública Federal, inicial, revisada, neta y bruta; INEGI (2020); Cárdenas (1994); Aguilar (1947); Santillán y Rosas (1962), bruta y neta; y el rubro financiero se estima con base en Santillán y Rosas (1962); INEGI (2020), inflación y PIB.

Las series de $\mathrm{S}$ y $\mathrm{R}$ brutas reproducen con mayor precisión los ingresos-egresos que registra la CHPF inicial y con menos cercanía a la serie revisada. No obstante, existen diferencias sustanciales en los años 1938-1940 y 1946 tanto para los ingresos como para los egresos. Al utilizar la edición inicial, se tiene el sesgo de no incorporar las correcciones que se van dando con el tiempo y esto representa un problema importante en ciertos años, como ya se mostró anteriormente. Las series de $\mathrm{S}$ y $\mathrm{R}$ neta provienen de una recopilación de los conceptos que forman el rubro financiero para 
llegar a los datos netos de 1935 a $1961,{ }^{14}$ lo cual implicaría una mejora. Sin embargo, este ajuste sufre del problema indicado de hacerlo sobre las series de la CHPF en su versión inicial y no en la revisada.

Las series ingresos-egresos de las EH muestran importantes inconsistencias en relación con las series de la CHPF inicial y revisada; pareciera que unos años se tomó de una versión y en otros de otra. Por el lado de los ingresos se acercan a las series de la CHPF bruta, tanto a la inicial como a la revisada, más a la segunda que a la primera. Las EH tienen coincidencias plenas, las cuales definimos como aquellas en que la diferencia en términos absolutos es cero, con la CHPF inicial y revisada en varios años, pero no necesariamente en los mismos años. En los egresos la situación es la contraria. Las EH parecen seguir con mayor fidelidad la de la CHPF inicial con un número mayor de coincidencias plenas, mientras que la cHPF revisada tiene un número menor. En el balance observamos que la EH es más cercana a la CHPF inicial que a la revisada, pero que considerada como un todo es inconsistente con una y con la otra.

Respecto a las deficiencias de la fuente secundaria de la EH, el estudio de Schlefer (2008) alude a las inconsistencias mencionadas, pero deja de mencionar otros conceptos de lo que hemos llamado el rubro financiero, ${ }^{15}$ los cuales si no se excluyen también crean distorsiones en los resultados. Schlefer (2008, p. 227, apéndice A) apunta lo siguiente:

Las estadísticas fiscales que se utilizan generalmente provienen del Instituto Nacional de Estadística e Informática. Las Estadísticas históricas de México del INEGi usan la mejor y más básica fuente de las cuentas fiscales: la Cuenta de la Hacienda Pública Federal de la Secretaría de Hacienda [...] Desafortunadamente, la manera que las Estadísticas Históricas y otras fuentes secundarias reportan las estadísticas fiscales involucra serios problemas. Por un lado, la información de Estadísticas Históricas anterior a 1980 trata frecuentemente los préstamos como parte de los ingresos y los incluyen en los mismos. Obviamente, si los préstamos son incluidos en los ingresos entonces no hay tal cosa como déficit o superávit (excepto en tanto que el gobierno se sobre endeude o desendeude en un año cualquiera). El problema se puede corregir fácilmente: Estadísticas Históricas ofrece el monto de préstamos, de tal manera uno puede deducirlo y obtener el ingreso real, como yo lo he hecho [...] El otro problema mayor -encontrado en muchas estadísticas fiscales mexicanas provenientes de fuentes secundarias, así como en Estadísticas Históricas y raramente identificado- es más difícil de corregir. Las amortizaciones se incluyen en los egresos, así como los pagos de intereses de la deuda [...] lo que se denomina apropiadamente egresos brutos, pero este frecuentemente no se etiqueta debidamente, lo cual es un error y es muy problemático. La amortización es también frecuentemente incluida en los egresos de las empresas públicas, donde es particularmente difícil de detectar o filtrar.

${ }^{14}$ El libro de Santillán y Rosas (1962) registra sólo las series que van de 1935 a 1961 debido a la fecha de su publicación en 1962.

${ }^{15}$ En los ingresos brutos Schlefer no incluye los subsidios, los ingresos virtuales y la recuperación de capital; en los egresos brutos, los subsidios compensados con egresos, otros egresos virtuales, egresos pendientes de pago y egresos compensados con recuperación de deuda. 


\section{SERIES PRIMARIAS NETAS: UNA COMPARACIÓN}

El inconveniente de utilizar las series primarias en términos brutos se evita a través de ajustar las cifras brutas por el rubro financiero y así obtener la serie en términos netos, en este caso la cHPF revisada; ${ }^{16}$ o utilizar la serie del Banco de México, quien consigna en sus Informes Anuales (en adelante BMiA) que es neta por construcción, pues se estima por el lado del financiamiento y además evita la complejidad de la contabilidad gubernamental. Ambas series tienen un impacto macro definido en la economía y son apropiadas para evaluar la política fiscal. Es también explicable que ambas series difieran en alguna medida pues su construcción corresponde a metodologías distintas. Sin embargo, encontramos diferencias significativas entre ellas para ciertos años, lo que da lugar a interpretaciones divergentes y esto será más relevante en ciertos episodios que en otros. Como ya se comentó, por diferencia significativa entendemos que es mayor que el promedio de dichas diferencias en términos absolutos y como porcentaje del PIB para el periodo de estudio. La interrogante en este punto es determinar cuál de estas dos series del balance fiscal es la más precisa para evaluar la política fiscal. ${ }^{17}$

La confrontación del balance fiscal de estas dos series muestra que hay diferencias importantes en 1936, 1938, 1942, 1947-1949 1951 y 1954. Para contrastar la serie de la cHPF revisada neta y la del вміA con mayor evidencia describiremos a grandes rasgos la política fiscal, la actividad económica y la inflación de cada periodo donde se localizaron las discrepancias.

\section{Subperiodo 1936 y 1938}

Los antecedentes son que en 1935 existió una caída del nivel de los precios, actividad económica dinámica, pues se estaba en el proceso de recuperación posterior a la crisis de 1929-1933, y de un superávit de finanzas públicas. ${ }^{18}$ En 1936 se inicia una política expansionista fiscal y monetaria bajo el nuevo secretario de Hacienda, Eduardo Suárez (Martín, 2019), quien sustituye al secretario Bassols en junio de 1935 (Suárez, 1977), durante la crisis política entre el presidente Cárdenas y el expresidente Calles. ${ }^{19}$ La inflación empieza a ascender ${ }^{20}$ la actividad económica se acelera a 8.0 \%

${ }^{16}$ Para realizar este proceso consideramos el rubro financiero que calculan Santillán y Rosas (1962) y se aplicó a la serie de la cHPF revisada, por ser la más actualizada en relación con la inicial, para así obtenerla en términos netos. Cabe aclarar que desconocemos qué tan preciso es el cálculo de Santillán y Rosas (1962) del rubro financiero, pues a pesar de una meticulosa presentación del mismo desconocemos si utilizó las series iniciales o revisadas de empréstitos, amortizaciones y otros componentes de ese rubro.

${ }^{17}$ En general los balances, déficits y superávits que se mencionan y las discrepancias entre ellos pueden parecer mínimos debido a la magnitud de estas variables en la actualidad para México y otros países emergentes. Sin embargo, como comentaremos en detalle en el siguiente apartado, esta magnitud debe ser escalada también respecto a los ingresos del gobierno federal, los cuales eran mucho más pequeños que en la actualidad.

${ }^{18}$ El superávit fue de acuerdo con el BMIA de $0.9 \%$ del PIB y para la chPF revisada neta de 0.5 por ciento.

${ }^{19}$ Véase González (1981) para un detallado relato de este momento histórico.

${ }^{20}$ De una inflación negativa al inicio del año se pasa a $12.5 \%$ a tasa anual en diciembre y alcanza un pico de $25.6 \%$ en junio de 1937. Como dato comparativo tenemos que la inflación externa, para lo cual utilizamos la tasa anual fin de periodo de Estados Unidos, registró $3.6 \%$ en 1936 y -2.8 \% en 1937; esto sugiere que no hubo impacto externo en la inflación interna y que su origen es nacional. Los datos que se citan en el estudio para la inflación de México provienen del INEGI (2020) y para Estados Unidos del Federal Reserve Bank of St. Louis, (2020). 
por encima del PIB potencial, ${ }^{21}$ y el superávit fiscal del año anterior pasa a ser un déficit equivalente a $1.3 \%$ del PIB, de acuerdo con el BMIA, pero las cifras de la cHPF revisada neta indican que se mantiene un superávit de $0.6 \%$ del PIB. Desde nuestro punto de vista, el escenario económico expansivo y sus consecuencias en inflación sugiere más un déficit que un superávit fiscal.

El caso de 1938 se explica por la expansión económica de los años 1936 y 1937, el ambiente complicado de la nacionalización de la industria petrolera y la devaluación de marzo, la cual requería una etapa de estabilización. Por ello, el déficit bajo de $0.2 \%$ del PIB estimado por el BMIA es más consistente que un déficit de -1.1 \% del PIB propuesto por la CHPF (véase cuadro 1).

\section{Subperiodo 1942}

En este episodio podríamos añadir el año 1943, el cual se encuentra en el promedio de la discrepancia al de 1942, que se ubica ligeramente arriba del mismo. En estos años localizamos otra diferencia significativa entre la serie del BMIA y la de la CHPF revisada neta. El antecedente es que se reinicia una política expansionista en lo fiscal y monetario en 1941 y 1942, por lo que hay que estabilizarla en 1943. La inflación fue de $0.8 \%$ a finales de 1940 , pero posteriormente ascendió a 12.2 y $11.1 \%$ a finales de los dos años posteriores, parcialmente influida por la inflación externa. ${ }^{22}$ La actividad económica crecía aceleradamente a 9.7 y 5.7 \% en 1941 y 1942, respectivamente; por tanto, en ambos años la tasa de crecimiento estuvo por encima del PIB potencial (véase cuadro 1 ). ${ }^{23}$

El déficit del bmia fue de $1.8 \%$ del PIB y el de la chPF revisada neta de $1.0 \%$ del PIB en 1942. El signo es el mismo y ambas cifras reflejan una economía en expansión. En 1943 es necesario estabilizar, pues la inflación tiene un repunte importante de $24.6 \%,{ }^{24}$ en un contexto de fuertes entradas de capital. ${ }^{25}$ La actividad económica se reduce y crece por debajo del PIB potencial. El BMIA estima un superávit de $0.2 \%$ del PIB y, en contraste, el déficit de la CHPF revisada neta fue de $-0.5 \%$. El escenario económico sugiere más una restricción presupuestal y un superávit más que un déficit.

\section{Subperiodo 1947-1949}

El periodo 1947-1949 muestra la mayor diferencia entre la del BMIA y la de la cHPF revisada neta. El BMIA reporta un superávit de $0.3 \%$, un déficit de $1.0 \%$ y otro superávit de $0.3 \%$ del PIB en esos años; esto es, un déficit acumulado de $0.5 \%$ del PIB. Las series de la chPF revisada neta reportan unos déficits de 1.1, 2.7 y $1.7 \%$ en los mismos años; esto sugiere una expansión fiscal considerable

${ }^{21}$ El PIB potencial es una variable no observable que se estima estadísticamente para representar la máxima capacidad de producción de la economía. La estimación del PIB potencial para ese año fue de $4.4 \%$ y la tasa del PIB observado fue de $8 \%$. Esta diferencia implica presiones de demanda ante una oferta limitada en la economía. Las estimaciones del PIB potencial son propias y se utiliza el PIB real cuyos datos provienen del INEGI (2020).

${ }^{22}$ La inflación fin de periodo a tasa anual de Estados Unidos fue de 12.4\% en el periodo 1941-1942; la equivalente mexicana fue de $11.7 \%$. Si bien las inflaciones en ambos países son similares hay que tener presente que en aquel entonces los bienes comerciables eran relativamente pocos, por lo que la inflación externa no se transmite a la interna más que parcialmente.

${ }^{23}$ En efecto, la tasa del PIB potencial era de 5.1 por ciento.

${ }^{24}$ La inflación externa disminuye a $2.3 \%$, pero el componente externo de la base monetaria pasa de $4.6 \%$ del PIB en 1942 a $9.0 \%$ del PIB en 1943. Esto obliga a una esterilización de esos fondos y al superávit observado.

25 Torres (1979, p. 177) cita al director del Banco de México, Eduardo Villaseñor, quien al describir las dificultades económicas en el año de 1943 señala que el "excedente de la balanza comercial que resultaba del aumento de las exportaciones y de las entradas crecientes de capital del exterior” redundaría en inflación. 


\section{GRÁFICA 1. BALANGE FISCAL: CHPF REVISADA NETA $V S$ BMIA}

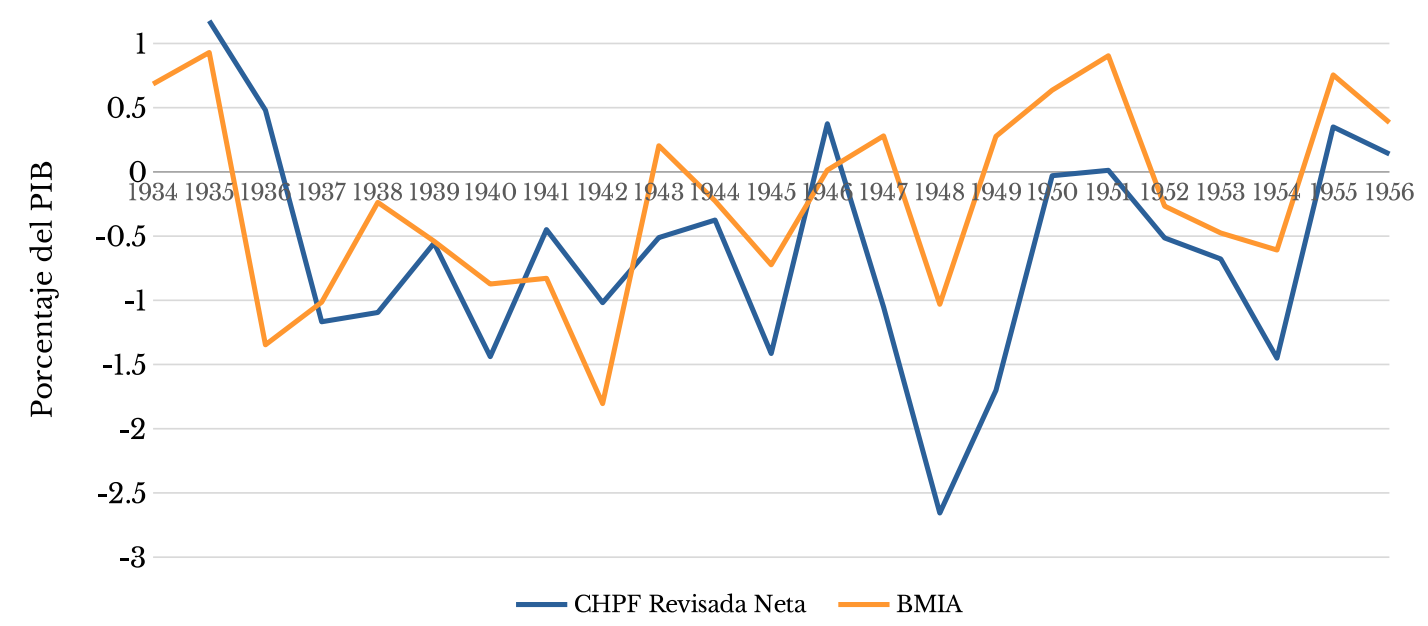

Fuentes: Cuenta de la Hacienda Pública Federal, inicial, revisada, neta y bruta, Secretaría de Hacienda y Crédito Público (1934-1955); INEGI (2020); Cárdenas (1994); Aguilar (1947); Santillán y Rosas (1962), bruta y neta; y el rubro financiero se estima con base en Santillán y Rosas (1962), INEGI (2020) inflación y PIB. Estimación propia, PIB potencial.

para la época con un déficit acumulado de $5.4 \%$ del PIB. Desde nuestra perspectiva, el contexto económico no parece respaldar el signo y magnitud de la serie de la cHPF revisada neta (véase gráfica 1).

En efecto, en 1947 se tiene la continuación del esfuerzo de estabilización iniciado en 1946 con apoyo del Fondo Monetario Internacional (FMI) para reducir las presiones inflacionarias que al final de este último año había alcanzado $17.8 \%$, lo que hace que al terminar 1947 la inflación era ya de $1.1 \%$ negativa. El crecimiento económico se desaceleró a $3.4 \%$, cuando estaba creciendo el año anterior a $6.6 \%$ por encima del PIB potencial. Este escenario denota más estabilización que expansión. El Banco de México (1940-1963), específicamente en los años de 1947 a 1953 muestra que el dato original era un déficit, como lo muestra la serie de la chpF revisada neta, pero que revisiones sucesivas corrigen a un superávit. De esta manera, en términos de signo, hubo revisiones que explican el cambio, lo cual es consistente con el dato del BMIA de un superávit. ${ }^{26}$

En 1948 sí hay coincidencia de signo en las dos series. El punto discordante es la magnitud. Para la serie del BмIA el dato es significativo, $1.0 \%$ del PIB, pero de menor magnitud que el de la serie de la cHPF revisada neta que alcanza un déficit extremadamente alto de $2.7 \%$ del PIB, no visto en el periodo de estudio, 1934-1956 (véase cuadro 1). En este año la administración alemanista inicia una expansión moderada en el primer semestre del año, la cual implica una inflación en ascenso de una cifra negativa de $2.5 \%$ en enero a otra positiva de $10.4 \%$ en julio. ${ }^{27}$ Esto conduce a

${ }^{26}$ Para el año 1947 la serie de la CHPF inicial al revisarse tuvo una reducción de $0.7 \%$ del PIB en ingresos y un aumento de $0.4 \%$ del PIB en egresos, lo cual al calcular el balance rindió una diferencia importante de $1.1 \%$ del PIB. El rubro financiero fue menor ese año, por lo cual el balance de la CHPF revisada neta fue de $1.1 \%$ del PIB. El balance de la cHPF inicial muestra un superávit que se revisa a lo largo de los cinco años siguientes para convertirse en déficit.

27 De acuerdo con el Banco de México (1948, p. 13), la retirada del Banco de México del mercado cambiario fue el 22 de julio de 1948 . 
la crisis cambiaria de 1948. Sin embargo, a partir de la devaluación, durante el segundo semestre, hubo un esfuerzo de estabilización. ${ }^{28}$ Esto sugiere que el déficit no podía alcanzar la cifra que plantea la serie de la CHPF revisada neta.

En el 1949 es necesario mantener la estabilización de la economía, pues el tipo de cambio estaba en flotación y de no hacerlo este no alcanzaría un nivel que fuera aceptable para la administración alemanista y congruente con el programa económico con el FMI. En el caso de 1949, el informe anual del Banco de México (1949, cuadro 9, p. 51) señala la existencia de un superávit y dos años después (1951, p. 26), al hablar del superávit de ese año, constata que: "Al igual que en los años de 1949 y 1950, el gobierno federal obtuvo un superávit en su presupuesto.” Planteamientos que sugieren que el déficit alto que muestra la serie de la chPF revisada neta es exagerado y su signo equivocado.

La conclusión es que las dos series que en principio cumplen con la metodología adecuada para evaluar la política fiscal, la del BMIA parece ser la más consistente con la evidencia del contexto histórico en los puntos críticos de comparación.

\section{PRoblemática DE UTILIZAR SERIES SECUNDARIAS: UN ESTUdio DE CASO}

En la sección anterior observamos los problemas de consistencia estadística en la serie de la CHPF revisada neta, lo cual induce a errores de interpretación. El caso es todavía más grave cuando se utiliza una serie secundaria, como la $\mathrm{EH}$, que es inconsistente debido a que combina las series de la CHPF brutas, inicial y revisada. La importancia de comentar esta opción es que la corriente de historia económica representada por Cárdenas $\left(1994,2008\right.$ y 2015) y otros autores ${ }^{29}$ mantiene una interpretación con base en esta evidencia empírica imprecisa.

Nuestra perspectiva, como se desprenderá de los argumentos que se presentarán, es que los economistas anteriores a este autor estaban esencialmente en lo correcto respecto al sesgo de una política expansiva e inflacionaria del periodo de examen, pero no presentaron una evidencia estadística contundente al respecto. ${ }^{30}$ De esta manera, la evidencia presentada por Cárdenas (1994, 2008 y 2015) dio más peso a sus argumentos y permeó como la interpretación dominante. Nuestra posición en esta cuestión es similar a la de Solís (1970) y otros, pero esta vez presentamos una mejor argumentación y mayor evidencia estadística validada por una revisión metodológica de las series estadísticas disponibles. ${ }^{31}$

${ }^{28}$ El Banco de México (1948, p. 25) señala: “El gobierno federal dictó las medidas necesarias para adaptar su política fiscal a las nuevas condiciones creadas por la devaluación monetaria. Considerando que los efectos inflacionarios del déficit presupuestal impedirían conseguir el equilibrio de la balanza de pagos por su tendencia a elevar las importaciones, decidió que en lo sucesivo los gastos públicos se ajusten estrictamente a los ingresos reales y limitó el programa de obras públicas exclusivamente a los recursos que provengan de impuestos."

${ }^{29}$ Entre otros autores que retoman el planteamiento o uno similar encontramos a Moreno-Brid y Ros (2010) y F. Suárez $(1977,2005,2012)$.

${ }^{30}$ Entre otros autores que representan la perspectiva tradicional son Solís (2004), Urquidi (1951), Palacios (1953), Turrent (2015).

${ }^{31}$ Véase Martín (2019), quien contrapone la argumentación de Cárdenas (1994, 2008, 2015) y otros y ofrece evidencia empírica en las líneas que presentamos en este estudio respecto al sexenio cardenista. 
Para todos los analistas del periodo en examen, la variable del balance público ${ }^{32}$ es clave, pues es la causa que al demandar el crédito del banco central incremente la oferta monetaria y la inflación. Su trayectoria es vital para explicar qué sucedió en la economía y su magnitud para medir el impacto. Por ello, Cárdenas (1994, 2008, 2015) y otros se apoyan en el balance fiscal y al utilizar la fuente secundaria de la EH en sus investigaciones encuentran soporte a nuevas afirmaciones. En efecto, estos autores plantean que la caracterización de la política económica de 1934 a 1956 ha sido interpretada erróneamente por la perspectiva tradicional de Solís (1970) y otros. En particular, Cárdenas (2008) sostiene, con la evidencia empírica ofrecida por la $\mathrm{EH}$, que el relato de la expansión del gasto público financiado con emisión primaria es infundado ya que:

La política hacendaria fue también muy mesurada [...] El déficit fiscal fue más bien limitado a lo largo de todo el periodo de "crecimiento con inflación" [...] Se puede afirmar que, en promedio, el déficit fiscal del gobierno federal fue equilibrado a lo largo de ese periodo. En forma acumulada el déficit vs superávit, el resultado global del saldo de las finanzas públicas entre 1934 y 1956 fue de sólo 0.2 \% del PIB. El déficit más alto llegó a $1.6 \%$ del PIB en 1948, debido a la política compensatoria del gobierno de esos años. De hecho, en sólo 6 años de 23 considerados, el gobierno federal ejerció un déficit igual o mayor a $1 \%$ del producto interno bruto (p. 838) [cursivas mías].

En relación con esta argumentación destacamos tres aspectos que se prestan a debate: $a$ ) la imprecisión ya comentada de la serie de la EH y que se hará evidente al compararla con la serie del вміА; $b$ ) la magnitud de los déficits, los cuales son aparentemente pequeños, pero no tanto cuando se hace una comparación relevante; es decir, se escala a otra variable que ofrece una mejor referencia, en este caso son los ingresos del gobierno en lugar del PIB, y $c$ ) el tratamiento de los déficits como promedio del periodo y no individualmente, así como de su escasa ocurrencia en la etapa del desarrollo con inflación.

\section{Comparación de las series de las EH y del BMIA}

La confrontación del balance fiscal de las series de las EH y del BMIA muestra que hay diferencias significativas en varios años, cerca de la mitad de las observaciones. ${ }^{33}$ Además, la suma de las diferencias absolutas entre estas dos series es de $11.7 \%$ del PIB, una diferencia acumulada no desdeñable en un periodo de 25 años. ${ }^{34}$ Las discrepancias observadas son suficientes para distorsionar la interpretación historiográfica en general y en ciertos años clave; por ejemplo aquellos cercanos a una crisis, como en 1938 y 1948. Ilustraremos este caso con el análisis del subperiodo 1935-1938 y para ello haremos una breve descripción del marco macro (véase gráfica 2).

El tramo más representativo de la discrepancia total se localiza en la primera mitad del sexenio cardenista. Las condiciones en 1935 y 1936 de disciplina inicial y de posterior expansión fueron comentadas líneas arriba. La expansión fiscal y monetaria continúa en la primera mitad de 1937,

${ }^{32}$ Se puede tratar de un déficit que implicaría una presión en la economía o un superávit que podría ser insuficiente para mitigar un choque externo.

33 En particular, hay una diferencia significativa, esto es, por encima del promedio, en 1935-1938, 1941-1942, 1944, 1946-1947 y 1955 (véase cuadro 5).

${ }^{34}$ El promedio se obtiene de las diferencias en términos absolutos para evitar que las diferencias se cancelen por los signos contrarios de algunas de ellas. El promedio anual de $0.5 \%$ de la discrepancia no es significativo en sí mismo debido a que lo importante es cuando esta discrepancia es mayor en ciertos momentos, no en promedio a lo largo del periodo. 


\section{GRÁFICA 2. BALANCE FISCAL: EH VERSUS BMIA}

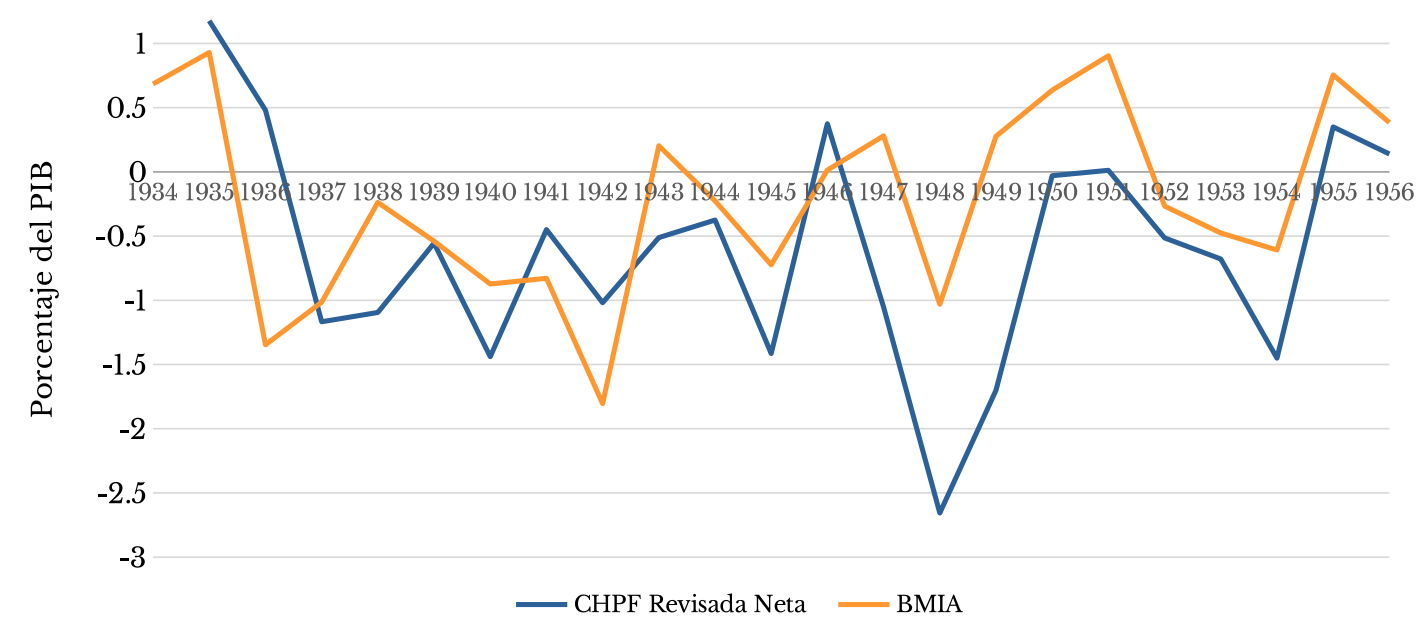

Fuentes: Secretaría de Hacienda y Crédito Público ([1934-1955]), Cuenta de la Hacienda Pública Federal, inicial, revisada, neta y bruta; INEGi (2020); Cárdenas (1994); Aguilar (1947); Santillán y Rosas (1962), bruta y neta; y el rubro financiero se estima con base en Santillán y Rosas (1962); INEGI (2020) inflación y PIB.

pero se frena hacia el final del año a partir de que la inflación alcanza un pico de $25.9 \%$ en junio. El crecimiento económico se desacelera a $3.3 \%$. El déficit fiscal disminuye a $1.0 \%$ del PIB según el вмIA у a $0.4 \%$ del PIB de acuerdo con las EH. En 1938 la situación era ya frágil por la sobrevaluación existente ${ }^{35}$ y el conflicto de la expropiación de la industria petrolera hizo ya insostenible el deterioro económico. La economía debía estabilizarse y, por tanto, el déficit público debía moderarse y, por ello, según el BMIA, alcanza $0.2 \%$ del PIB, mientras que las EH señalan $0.9 \%$ del PIB. Cifra, esta última, inconsistente con una estabilización posdevaluatoria en un contexto en que el gobierno carecía de financiamiento no primario.

Además de las discrepancias de año con año, la comparación agregada 1936-1938 muestra que el déficit acumulado del Bmia es de $2.5 \%$ del PIB, mientras que el de las EH es de $1.7 \%$ (véase cuadro 2).

\section{Magnitud del déficit fiscal}

El segundo aspecto es sobre la magnitud del déficit fiscal, la cual es engañosa por los niveles aparentemente bajos que registra. Tratar de calificar los déficits como altos o bajos es un problema que demanda una métrica defendible en dos sentidos. El primero es el financiero, ya que déficits bajos pueden ser problemáticos si no hay un financiamiento sano o déficits altos pueden no ser catastróficos si hay financiamiento y que la causa de los mismos sea una inversión que produzca con el tiempo el repago de la deuda incurrida en los plazos establecidos. El segundo sentido es la escala que se utiliza para evaluar qué tan sustentable es un déficit. El balance fiscal se escala convencionalmente como porcentaje del PIB, cuando esta variable refleja en realidad la capacidad financiera

${ }^{35}$ De acuerdo con Martín (2019, cuadro 1, p. 6), la valuación cambiaria que hasta mediados de 1936 estaba alrededor del equilibrio inicia un proceso de sobrevaluación. 
de la economía, no del gobierno. Esto tiene sentido desde el punto de vista de que existe una relación entre las capacidades financieras de la economía y el gobierno y, por ello, es una referencia generalmente aceptada. No obstante, esta relación depende del grado en que el gobierno puede extraer ingreso de esa economía, a través de financiamiento voluntario (bonos gubernamentales) o impuestos. ${ }^{36}$ En la época que nos ocupa no había financiamiento interno o externo voluntario por la problemática posrevolucionaria y los intentos al respecto fueron limitados y su resolución fue gradual a través de las décadas de 1940 y $1950 .{ }^{37}$ En consecuencia, una mejor variable para escalar el déficit gubernamental son los ingresos públicos y no el PIB.

En efecto, la extracción de impuestos o ingresos totales es lo que define la capacidad del gobierno para su gasto y es también en relación con esta variable que hay que juzgar la magnitud del déficit fiscal. Por ejemplo, los déficits de 1.3, 1.0, 1.8, y $1.0 \%$ del PIB en 1936, 1937, 1942 y 1948, respectivamente, implican 19.0, 15.9, 30.0 y $17.7 \%$ de los ingresos del gobierno federal de cada año, también respectivamente. ${ }^{38}$ Estos montos son significativos en relación con los ingresos, dados los tiempos con una baja recaudación, cuyo promedio en los años citados fue de $6.8 \%$ del PIB y, reiteramos, limitado acceso a los mercados de deuda (véase cuadro 3). ${ }^{39}$

Para dimensionar esto con el presente, los déficits fiscales del gobierno federal de los años seleccionados serían equivalentes a 3.4, 2.9, 5.4, y $3.2 \%$ del PIB, respectivamente, en la actualidad. ${ }^{40}$ Estas magnitudes serían cuestionables hoy en día, no obstante el acceso a financiamientos internos y externos sanos y a un manejo adecuado de la deuda en términos de plazo y tasa de interés. Con este análisis concluimos que los déficits en ciertos años no fueron pequeños de acuerdo con una escala más adecuada, y que la observación histórica muestra que fueron causa de crisis o perturbaciones importantes en la economía por su financiamiento primario.

\section{Promedio versus observaciones individuales}

En el tercer aspecto a debate, Cárdenas $(1994,2008,2015)$ plantea que el "promedio" de los déficits no fue importante en el periodo, pues sólo fue de $0.2 \%$ del PIB. Este planteamiento soslaya el punto de que el problema de los déficits se hace relevante, no por su comportamiento promedio a lo largo del tiempo, sino por lo que sucede en ciertos momentos. Por ejemplo, es posible tener déficits permanentemente, siempre y cuando la deuda crezca a un menor ritmo que el pis, lo que implica ganancias de productividad, capacidad de repago y un nivel de deuda manejable; asimis-

${ }^{36}$ No tenemos memoria de que en otros estudios el dimensionamiento déficit público se realice con base en los ingresos gubernamentales, esto probablemente debido a la convención general de hacerlo respecto al pIB y también a que el análisis que realizan quizá no lo demanda. En este caso reiteramos que importa no sólo argumentar utilizando el déficit público como proporción del PIB, sino añadir otra dimensión al análisis.

${ }^{37}$ Véase Bazant (1994) para un panorama general del proceso de renegociación de la deuda y del restablecimiento del crédito a México.

${ }^{38}$ El porcentaje del déficit en términos de los ingresos lo calculamos con la serie de déficit del Bмia (véase cuadro 2) y de los ingresos netos del gobierno federal de Santillán y Rosas (1962) (véase cuadro 3). Esta última serie es la adecuada para establecer esta relación ya que excluye de los ingresos lo correspondiente al rubro financiero.

${ }^{39}$ En el cuadro 3 se tienen los ingresos de las diversas fuentes estadísticas. El porcentaje promedio de los ingresos aquí citado fue calculado con base en las cifras netas de Santillán y Rosas (1962).

${ }^{40}$ De acuerdo con la SHCP (2020), los ingresos del gobierno federal representaron $18.1 \%$ del pIB en 2019 . El déficit del gobierno federal fue de $2.0 \%$ del PIB. 
mo, que su financiamiento sea sano y no primario. ${ }^{41} \mathrm{El}$ problema de los déficits es cuando tocan niveles significativos y su financiamiento es primario, por uno o más años, que hacen insostenible el equilibrio macroeconómico en el tiempo por su presión en inflación, tipo de cambio y balanza de pagos; en otras palabras, en una crisis cambiaria. ${ }^{42}$

Las crisis cambiarias del periodo, 1938 y 1948, provienen de un exceso de inversión sobre el ahorro asociado a un déficit fiscal correspondiente a uno o dos años en particular. Los déficits de 1936-1937 explican la crisis de 1938 y el déficit de 1948, la correspondiente a ese año. En contraste, en los años posteriores a las crisis económicas opera un proceso de estabilización macroeconómica, lo cual implica, por necesidad, moderar la política expansiva instrumentada después de haber ajustado el tipo de cambio; por ejemplo en 1939-1940. O también realizar un esfuerzo para bajar la presión inflacionaria y evitar el ajuste cambiario, por ejemplo en 1946-1947 y 1952-1953, en ambos casos con la intervención del Fondo Monetario Internacional. ${ }^{43}$ En estos dos últimos casos, los esfuerzos de estabilización no pudieron evitar las crisis de 1948 y de 1954 .

\section{Conclusiones}

Concluimos en este estudio que la fuente primaria del chPF bruta, versiones inicial y revisada, es inadecuada para evaluar la política fiscal. Esto es debido a que incluye rubros que no tienen impacto macroeconómico. El ajuste necesario lo realizan Santillán y Rosas (1962) y obtienen la serie de la CHPF neta al descontar el rubro financiero neto, lo cual es correcto, pero los resultados son inconsistentes por haber utilizado la CHPF en su versión inicial en lugar de la revisada. Al corregir esta falla se tiene una serie que es adecuada para la evaluación de la política fiscal. Sin embargo, la comparación con la del BMIA muestra que esta última es más consistente con la evidencia macroeconómica.

Las fuentes secundarias bajo estudio reproducen la imprecisión citada de la cHPF bruta, por lo que estudios que utilizan estas fuentes, como la serie de la EH y otras similares, son imprecisos y la interpretación que sostienen está sujeta a debate. Este es el caso de Cárdenas (1994, 2008, 2015) y otros autores.

Consideramos que el presente estudio contribuye a establecer las bases para la discusión de la política fiscal cuando es evaluada por el balance fiscal. Las interpretaciones acerca del periodo, por ofrecer un ejemplo, tomemos el sexenio cardenista, muestran que de una posición de fuerte crítica

${ }^{41}$ Véase Krugman y Wells (2013) sobre la racionalidad de mantener un financiamiento de mercado y no por emisión primaria del banco central. El financiamiento de mercado consiste en la emisión de bonos o préstamos internos o externos de acuerdo con una programación financiera adecuada de plazos y tasas. Sin embargo, en el periodo de estudio el financiamiento fue en gran medida primario; no obstante, de acuerdo con Gómez (1981), a partir de 1948 el financiamiento se fue complementando con las reservas bancarias de la banca privada en el banco central, lo cual aminoró la presión inflacionaria.

${ }^{42}$ La definición de crisis refiere a un cambio profundo y de consecuencias importantes y, por lo mismo, es un fenómeno temporal que, en el periodo de estudio, dura de uno a dos años. Posterior a este fenómeno sigue un periodo de estabilización que normalmente incluye una disminución de la magnitud de los déficits o incluso se incurre en superávits. Esto es lo que da cuerpo a una política de arranque y freno (stop and go).

${ }^{43}$ Por ejemplo, esto fue cierto para 1936-1937 y la crisis cambiaria de 1938, de la cual ya hemos hablado. Igualmente, la crisis de 1948 fue ocasionada fundamentalmente por los desbalances fiscales y el financiamiento primario de los años 1941-1946, que los programas de contención de 1946-1947 no pudieron detener. Al respecto de las crisis de estos años, véase Gómez (1981), Brothers y Solís (2001), Solís (2004), Moreno-Brid y Ros (2010), Suárez (2012), Cárdenas (2015), Turrent (2015) y Martín (2019), entre otros. 
y caracterización como una política expansiva (Palacios, 1953; Solís, 2004; Turrent, 2015; Urquidi, 1951, y otros) se pasa a otra de calificarla como una política responsable (Cárdenas, 1994, 2008, 2015; Suárez, 1977, 2005, 2012). Con la revisión metodológica y evidencia que aquí se presenta se retoma la primera posición con una argumentación más sólida. Asimismo, se abre el camino para nuevas avenidas de investigación (Martín, 2019, sobre el periodo cardenista) y revisión de interpretaciones que hoy parecen predominar y establecer un debate. Algunos ejemplos pueden ser si la política económica cardenista fue expansiva o no; si la política fiscal de Ávila Camacho tuvo un impacto rezagado y causó la crisis de 1948, o si la responsabilidad de la devaluación de 1954 corresponde al alemanismo.

\section{LISTA DE REFERENCIAS}

Aguilar, G. (1947). Los presupuestos mexicanos desde los tiempos de la colonia hasta nuestros días. México: s. e.

Anguiano, R. (1968). Las finanzas del sector público en México. México: Universidad Nacional Autónoma de México.

Banco de México (1940-1963). Informe anual [varios años]. México: Banco de México.

Bazant, J. (1994). La crisis y la segunda guerra mundial (1928-1945). En E. Cárdenas (ed.), Historia económica de México (pp. 320-347). México: Fondo de Cultura Económica.

Brothers, S. y Solís, L. (2001). Evolución financiera mexicana. En L. Solís (ed.), Obras: Textos de análisis económico (ensayos y escritos diversos) (vol. 1, pp. 369-628), México: El Colegio Nacional.

Cárdenas, E. (1994). La Hacienda pública y la política económica, 1929-1958. México: Fondo de Cultura Económica.

Cárdenas, E. (2008). El mito del gasto público deficitario en México (1934-1956). El Trimestre Económico, 75(4), 809-840. Dor: 10.20430/ete.v75i300.420

Cárdenas, E. (2015). El largo curso de la economía mexicana: De 1780 a nuestros días. México: Fondo de Cultura Económica.

Federal Reserve Bank of St. Louis (2020). Federal Reserve Bank of St. Louis | Economic Data, Monetary Rates, Economic Education [Org.]. Recuperado de https://fred.stlouisfed.org/

Gómez, A. (1981). Políticas monetaria y fiscal de México. México: Fondo de Cultura Económica.

González, L. (1981). Historia de la revolución, 1934-1940. Los días del presidente Cárdenas. México: El Colegio de México.

INEGi [Instituto Nacional de Estadística y Geografía] (2020). Estadísticas históricas de México. Recuperado de https://www.inegi.org.mx/

Isoard, C. (1979). Cuadros de información estadística. México: Secretaría de Hacienda y Crédito Público.

Krugman, P. y Wells, R. (2013). Macroeconomics. Nueva York: Worth Publishers.

Martín, S. (2019). El debate de la política económica cardenista: Una perspectiva contemporánea. América Latina en la Historia Económica, 26(1), 1-26. DoI: 10.18232/alhe.916

Moreno-Brid, J. y Ros, J. (2010). Desarrollo y crecimiento en la economía mexicana: una perspectiva histórica. México: Fondo de Cultura Económica. Recuperado de https://elibro.net/ereader/elibro demo/110888

Nacional Financiera (1964). La economía mexicana en cifras (SIBE). México: NAFINSA. Recuperado de http://bibliotecasibe.ecosur.mx/sibe/book/000006969 
Nacional Financiera (1972). La economía mexicana en cifras. México: NAFINSA.

Palacios, M. (1953). Dos documentos sobre política hacendaria mexicana. Problemas Agrícolas e Industriales de México, 5(1), 154-161.

Reynolds, C. (1977). Por qué el desarrollo estabilizador de México fue en realidad desestabilizador. El Trimestre Económico, 44(176), 997-1023.

Santillán, R. y Rosas, A. (1962). Teoría general de las finanzas públicas y el caso de México: por Aniceto Rosas Figueroa (y) Roberto Santillán López. México: Universidad Nacional Autónoma de México.

Schlefer, J. (2008). Palace politics: How the ruling party brought crisis to Mexico. Austin: University of Texas Press.

Secretaría de Hacienda y Crédito Público (1934-1963). Cuenta de la Hacienda Pública Federal [varios años: 1934-1963]. México: Autor.

Secretaría de Hacienda y Crédito Público (2020). Paquete económico y presupuesto [gubernamental]. Recuperado de https://www.finanzaspublicas.hacienda.gob.mx/es/Finanzas_Publicas/

Solís, L. (1970). La realidad económica mexicana: retrovisión y perspectivas. México: Siglo XXI Editores.

Solís, L. (2004). Evolución de la economía mexicana. En L. Solís (ed.), Obras: Textos de análisis económico (ensayos y escritos diversos) (vol. 9, pp. 333-682). México: El Colegio Nacional.

Suárez, E. (1977). Comentarios y recuerdos, 1926-1946. México: Porrúa.

Suárez, F. (1977). Bosquejo biográfico. En E. Suárez (ed.), Comentarios y recuerdos, 1926-1946 (pp. XXXI-CXXIV). México: Porrúa.

Suárez, F. (2005). Dos visiones de la política económica de México: un debate en la historia (1946 a 1970). En M. Romero (ed.), Historia del pensamiento económico de México, problemas y tendencias (1821-2000) (pp. 255-290). México: Trillas.

Suárez, F. (2012). Retórica, política económica y resultados del desarrollismo mexicano: 19321958. En M. Romero (ed.), Fundamentos de la política económica en México 1910-2010 (pp. 191 236). México: Universidad Nacional Autónoma de México.

Torres, B. (1979). Historia de la revolución mexicana, 1940-1952, México en la segunda guerra mundial. México: El Colegio de México.

Turrent, E. (2015). Historia del Banco de México. México: Banco de México.

Urquidi, V. (1951). El papel de la política fiscal y monetaria en el desarrollo económico. El Trimestre Económico, 18(72[4]), 636-653. 